\title{
Can Ultrasonographic Measurements of Gastric Motility Identify Pathophysiological Abnormalities of Functional Dyspepsia and Irritable Bowel Syndrome?
}

\author{
Hong Sub Lee \\ Department of Internal Medicine, Inje University Busan Paik Hospital, Busan, Korea
}

Article: Postprandial symptoms in patients with functional dyspepsia and irritable bowel syndrome: relations to ultrasound measurements and psychological factors

Steinsvik EK, Valeur J, Hausken T, Gilja OH

(J Neurogastroenterol Motil 2020;26:96-105)

The pathophysiology of functional gastrointestinal disorders (FGIDs) is incompletely understood. Based on improved understanding about low grade inflammation, motility disturbances, visceral hypersensitivity, gut microbiome, brain-gut axis, the nonspecific term "functional" will gradually disappear in future studies. ${ }^{1}$ Although various motility disturbances were found on many FGIDs, ${ }^{2,3}$ there are few sensitive and noninvasive tests to evaluate gastric motility in patients with unexplained gastrointestinal symptoms.

Many studies using single-photon emission computed tomography (SPECT) have evaluated the stomach motor disturbances in patients with upper gastrointestinal symptoms, ${ }^{4}$ functional dyspepsia (FD), ${ }^{5}$ gastroparesis, ${ }^{6}$ and diabetes mellitus. ${ }^{7}$ However, SPECT is expensive and potentially hazardous due to high radiation exposure. The ultrasonographic measurement of gastric motility is one of the noninvasive and inexpensive tests proposed as an alternative to barostat, magnetic resonance imaging, and SPECT.9

There is a little evidence about ultrasonographic evaluation of stomach function in patients with $\mathrm{FD}$ or diabetes mellitus. ${ }^{10} \mathrm{How}-$ ever, the problem of standardization and reproducibility was inevitable in all of ultrasound studies. Also, the heterogeneity of test meal or drink is something to consider. In some studies using the waterdrinking ultrasonography combined test, abnormalities of gastric emptying and accommodation were seen in FD patients. ${ }^{11,12}$ Another study using the test liquid meal showed that proximal stomach of FD patients was significantly smaller than that of healthy controls. ${ }^{13}$ The caloric content of test meal can influence gastric emptying. ${ }^{14}$ Therefore, the calorie and composition of test meal must be one of the confounding factors to affect the results.

Controversy exists as to whether stomach motor disturbances are associated with the symptoms of patients with FD. A metaanalysis showed about $40 \%$ of patients with FD have delayed gastric emptying. ${ }^{15}$ Some studies showed that severity of symptoms correlates with delayed gastric emptying. ${ }^{6,16}$ However, other studies revealed no or little difference in symptoms between patients with or without delayed gastric emptying. ${ }^{5,17,18}$ Also, FD subgroups are not

Received: December 4, 2019 Revised: None Accepted: December 8, 2019

(c) This is an Open Access article distributed under the terms of the Creative Commons Attribution Non-Commercial License (http://creativecommons. org/licenses/by-nc/4.0) which permits unrestricted non-commercial use, distribution, and reproduction in any medium, provided the original work is properly cited.

*Correspondence: Hong Sub Lee, MD, PhD

Department of Internal Medicine, Inje University Busan Paik Hospital, 75 Bokji-ro, Busanjin-gu, Busan 47392, Korea

Tel: +82-51-890-6989, Fax: +82-51-892-0273, E-mail: hslee@paik.ac.kr 
differentially related to abnormalities of stomach motor function. ${ }^{19}$ Although SPECT can quantify the amount of remaining material in the stomach, it cannot distinguish a patient with FD from that with idiopathic gastroparesis. Also, the utility of ultrasonography in these groups of patients is unknown.

In this issue of the Journal of Neurogastroenterology and Motility, Steinsvik et $\mathrm{al}^{20}$ performed a retrospective case-control study to investigate the parameters and symptoms in patients with irritable bowel syndrome (IBS) and FD by using ultrasonographic meal tests and questionnaires, compared with healthy controls. Subjects (FD: $n=94$, IBS: $n=88$, IBS + FD: $n=66$, and healthy controls: $\mathrm{n}=30$ ) were included. As a result, the enlarged antral area in the fasting status was found in patients with IBS and FD by using ultrasonographic meal tests (UMAT), compared with controls. Although symptom severity did not correlate with ultrasound measurement, epigastric discomfort and pain were associated with anxiety and neuroticism in a fasting status.

The reproducibility of antral area measurements in this research group was evaluated by intra-observer and inter-observer variance from a paper published in $1994 .^{21}$ Also, they reported the ideal time for the ultrasonographic measurement of accommodation. ${ }^{22}$ A previous cross-sectional study by this group showed that $36 \%$ of FD patients by using ultrasound assessment have impaired gastric accommodation. ${ }^{23}$

The meaning of this study is that it is the first identification of gastric motility disturbances of IBS by using ultrasonography. This result correlated well with the study using wireless $\mathrm{pH} /$ pressure recording capsules. ${ }^{24}$ In that study, antral motility parameters were significantly impaired in children with IBS, compared with controls.

However, the UMAT used in this study is operator dependent. It requires a skilled observer. In some cases including excessive subcutaneous fat, gas, and anatomic variations, examination was not satisfactory as a result of poor visualization of the stomach. ${ }^{25}$ Further studies using the protocol used in this study are needed in non-specialized centers for easy use of ultrasound in stomach motor disturbances.

Can ultrasonographic measurements of gastric motility identify pathophysiological abnormalities of FD and IBS? Maybe yes, but there is still a long way to go.

\section{Financial support: None.}

\section{Conflicts of interest: None.}

\section{References}

1. Schmulson MJ, Drossman DA. What is new in Rome IV. J Neurogastroenterol Motil 2017;23:151-163.

2. DuPont AW, Jiang ZD, Harold SA, et al. Motility abnormalities in irritable bowel syndrome. Digestion 2014;89:119-123.

3. Storlid EL, Hausken T, Lied GA, Gilja OH, Hatlebakk JG. Gastric accommodation in healthy subjects studied by ultrasound, manometry, and impedancemetry. Neurogastroenterol Motil 2018;30:e13249.

4. Park SY, Acosta A, Camilleri M, et al. Gastric motor dysfunction in patients with functional gastroduodenal symptoms. Am J Gastroenterol 2017;112:1689-1699.

5. Dibaise JK, Islam RS, Dueck AC, Roarke MC, Crowell MD. Psychological distress in Rome III functional dyspepsia patients presenting for testing of gastric emptying. Neurogastroenterol Motil 2016;28:196-205.

6. Ardila-Hani A, Arabyan M, Waxman A, et al. Severity of dyspeptic symptoms correlates with delayed and early variables of gastric emptying. Dig Dis Sci 2013;58:478-487.

7. Chedid V, Brandler J, Vijayvargiya P, Park SY, Szarka LA, Camilleri M. Characterization of upper gastrointestinal symptoms, gastric motor functions, and associations in patients with diabetes at a referral center. Am J Gastroenterol 2019;114:143-154.

8. Muresan C, Surdea Blaga T, Muresan L, Dumitrascu DL. Abdominal ultrasound for the evaluation of gastric emptying revisited. J Gastrointestin Liver Dis 2015;24:329-338.

9. Ang D. Measurement of gastric accommodation: a reappraisal of conventional and emerging modalities. Neurogastroenterol Motil 2011;23:287291.

10. Darwiche G, Almér LO, Björgell O, Cederholm C, Nilsson P. Measurement of gastric emptying by standardized real-time ultrasonography in healthy subjects and diabetic patients. J Ultrasound Med 1999;18:673682.

11. Kugler T. The usefulness of water-drinking ultrasonography combined test for evaluating patients with functional dyspepsia. Korean J Gastroenterol 2015;66:92-97.

12. Hata T, Kato M, Kudo T, et al. Comparison of gastric relaxation and sensory functions between functional dyspepsia and healthy subjects using novel drinking-ultrasonography test. Digestion 2013;87:34-39.

13. Fan XP, Wang L, Zhu Q, Ma T, Xia CX, Zhou YJ. Sonographic evaluation of proximal gastric accommodation in patients with functional dyspepsia. World J Gastroenterol 2013;19:4774-4780.

14. Mazzawi T, Bartsch E, Benammi S, et al. Gastric emptying of low- and high-caloric liquid meals measured using ultrasonography in healthy volunteers. Ultrasound Int Open 2019;5:E27-E33.

15. Quartero AO, de Wit NJ, Lodder AC, Numans ME, Smout AJ, Hoes AW. Disturbed solid-phase gastric emptying in functional dyspepsia: a meta-analysis. Dig Dis Sci 1998;43:2028-2033.

16. Perri F, Clemente R, Festa V, et al. Patterns of symptoms in functional dyspepsia: role of Helicobacter pylori infection and delayed gastric emptying. Am J Gastroenterol 1998;93:2082-2088.

17. Wuestenberghs F, Juge M, Melchior C, Desprez C, Leroi AM, 
Gourcerol G. Association between symptoms, quality of life, and gastric emptying in dyspeptic patients. J Neurogastroenterol Motil 2019;25:534543.

18. Hafeez M, Hussain F, Salamat A, Khan MB. Gastric emptying scintigraphy in postprandial distress syndrome. Pak J Med Sci 2018;34:27-31.

19. Vanheel H, Carbone F, Valvekens L, et al. Pathophysiological abnormalities in functional dyspepsia subgroups according to the Rome III criteria. Am J Gastroenterol 2017;112:132-140.

20. Steinsvik EK, Valeur J, Hausken T, Gilja OH. Postprandial symptoms in patients with functional dyspepsia and irritable bowel syndrome: relations to ultrasound measurements and psychological factors. J Neurogastroenterol Motil 2020;26:96-105.

21. Hveem K, Hausken T, Berstad A. Ultrasonographic assessment of fasting liquid content in the human stomach. Scand J Gastroenterol
1994;29:786-789.

22. Gilja OH, Hausken T, Wilhelmsen I, Berstad A. Impaired accommodation of proximal stomach to a meal in functional dyspepsia. Dig Dis Sci 1996;41:689-696.

23. Steinsvik EK, Hausken T, Gilja OH. The ultrasound meal accommodation test in 509 patients with functional gastrointestinal disorders. Scand J Gastroenterol 2016;51:788-794.

24. Devanarayana NM, Rajindrajith S, Bandara C, Shashiprabha G, Benninga MA. Ultrasonographic assessment of liquid gastric emptying and antral motility according to the subtypes of irritable bowel syndrome in children. J Pediatr Gastroenterol Nutr 2013;56:443-448.

25. Haruma K, Kusunoki H, Manabe N, et al. Real-time assessment of gastroduodenal motility by ultrasonography. Digestion 2008;77(suppl 1):4851. 